\title{
Comparative Analysis of Laser Treatment on Solid and Yarn Dyed Cotton Fabric
}

\author{
Marzia Islam ${ }^{1}$, Kamrun Nahar ${ }^{2}$, Jannatul Ferdush ${ }^{2}$ and Tarifun Akter ${ }^{2}$ \\ ${ }^{1,2}$ Lecturer, Department of Textile Engineering, Northern University Bangladesh, Bangladesh
}

*Corresponding author: Marzia Islam, Lecturer, Department of Textile Engineering, Northern University Bangladesh, Bangladesh.

Received Date: November 04, 2019

Published Date: November 08, 2019

\begin{abstract}
In this study, Woven fabric was treated by a carbon dioxide $\left(\mathrm{CO}_{2}\right)$ laser. Two types of $100 \%$ cotton fabrics one is solid dyed, and another is yarn dyed samples were treated with a $\mathrm{CO}_{2}$ laser under the same conditions with two laser processing parameters, namely, (i) resolution and (ii) pixel time, were used to adjust the laser power. After laser treatment, the color properties like Color co-ordinate value following CIE $\mathrm{L}^{*} \mathrm{a}^{*} \mathrm{~b}^{*}$ method and Metamerism Index were measured. Abrasion pilling resistance and tear strength were also determined. Then the results were analyzed thoroughly and built up a comparison among them.
\end{abstract}

Keywords: Abrasion pilling resistance; Cotton; Color properties; Laser; Pixel time; Resolution,

\section{Introduction}

Laser, a water free physical treatment which provides precision in processing by exposing the textile fabric to laser radiation using efficient intensity. It is considered a clean process that offers low cost and low environmental impact causing the photo-degradation of dye without damaging the textile material [1-3]. From nineteenth century laser is being used in apparel industry [4]. $\mathrm{CO}_{2}$ laser is most suitable for textile materials among all the laser processing machines which are recently available $[5,6]$. Specially the $\mathrm{CO}_{2}$ pulsed laser, unlike other infra-red lasers, has overcome the shortcoming of the continuous wave mode, causing no thermal damage effect [7]. The $\mathrm{CO}_{2}$ laser is not a good conductor of heat and electricity because its wavelength can be easily absorbed by textiles [8]. The impact of laser treatment is emphasized on the color destruction of $100 \%$ cotton fabric [9]. Although the effect of laser treatment on $100 \%$ cotton woven fabric has been studied in recent years [10]. The laser treatment for synthetic textile materials such as polyethylene terephthalate (PET) and polyamide (nylon) has been also developed over many years [11,12].

The intent of this study is to assess the effect of $\mathrm{CO}_{2}$ laser treatment on the physical and color properties of $100 \%$ cotton woven fabrics having the different structure but were made with same yarn count and weight. A carbon dioxide laser treatment was investigated on the fabrics with different levels of intensity in terms of resolution and pixel time. For that reason, it is important to analyze the impact of laser treatment on the physical properties of the tested fabrics. Different measures such as the tear strength, pilling, color fading effect by evaluating color value have been carried out to establish a most preferable effect.

\section{Materials \& Methods}

\section{Cotton fabric}

Two samples of $100 \%$ cotton fabric were collected from Evince Ltd. Bangladesh. The specifications of the samples are shown in Table 1. Both samples were dyed with reactive dye. But the major difference between sample 1 and sample 2 was that the first one is solid dyed and second one is yarn dyed. The two fabrics were conditioned under standard atmospheric condition of $20 \pm 20^{\circ} \mathrm{C}$ and a relative humidity of $65 \pm 2 \%$ before treatment.

Table 1: Fabric specification.

\begin{tabular}{|c|c|c|}
\hline Fabric Parameter & Solid dyed fabric & Yarn dyed fabric \\
\hline Fabric GSM & 120 & 121 \\
\hline $\begin{array}{c}\text { Fabric density (EPI, } \\
\text { PPI) }\end{array}$ & $133^{*} 72$ & $120 * 80$ \\
\hline Warp count (Ne) & 40 & $40 / 1$ \\
\hline Weft Count (Ne) & 40 & $40 / 1$ \\
\hline Dye & Reactive & Reactive \\
\hline
\end{tabular}




\section{Laser treatment}

The sample was treated with a $\mathrm{CO}_{2}$ laser machine with specifications as shown in Table 2. There are two major parameters of laser treatment one is resolution, and another is pixel time. Resolution is expressed in dpi defined as a parameter that controls the intensity of laser spots per unit area. Pixel time is expressed in $\mu \mathrm{s}$ defined as a parameter that controls the time of laser processing to create the required effect. The resolution of the laser beam was set to 32 dots per inch (dpi) with pixel time of $30,40,50 \mu$ s respectively when the laser ray was applied on both solid and yarn dyed fabric .
A square pattern of $20 \mathrm{cmX} 20 \mathrm{~cm}$ was executed according to various combinations $(32,30),(32,40),(32,50)$ of resolution and pixel time (Figure 1).

Table 2: Specification of laser engraving machine.

\begin{tabular}{|c|c|}
\hline Model & HT-1325 \\
\hline Laser medium & C02 \\
\hline Wavelength & 10.6 \\
\hline Pixel time & $30,40,50$ \\
\hline Resolution & 32 \\
\hline
\end{tabular}

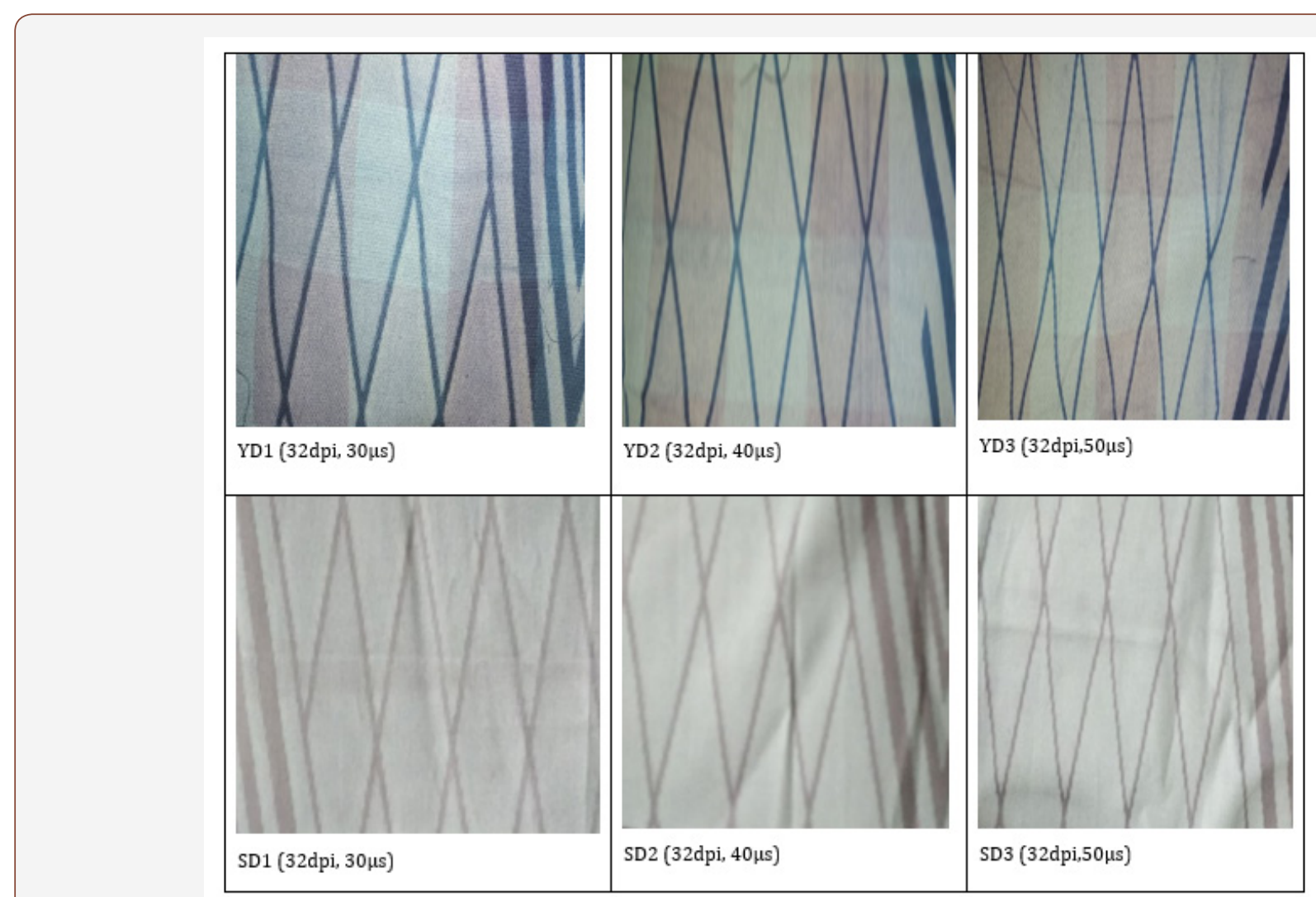

Figure 1: Visual appearance of laser treated sample.

\section{Color measurement}

The Color difference of the fabrics were measured by using a spectrophotometer Gretag Macbeth Color-Eye7000A spectrophotometer. The parameters of D65 daylight with a $10^{\circ}$ standard observer were used during color measurement. Before the measurement of color, the samples were conditioned at $20 \pm 2^{\circ} \mathrm{C}$ and a relative humidity of $65 \pm 2 \%$. $\Delta \mathrm{E}$ was obtained as color difference of the treated samples.

\section{Abrasion pilling resistance measurement}

Abrasion pilling resistance was measured by ICI pilling box tester by JIS L 1076-2006 A method. This test was done on total 8 samples (before and after laser treated sample on solid and yarn dyed both) and the test duration was 10 hours i.e. each sample was abraded for 10 hours. Then it was matched with grading scale of pilling and graded each sample individually according to the visual change.

\section{Tear Strength}

The tear strength of the treated and untreated solid and yarn dyed fabric was measured in both warp and weft way using the tearing strength tester according to JISL 1096 method D (pendulum). All the measurement was taken in N (newton).

\section{Results and Discussion}

\section{Color co-ordinate value}

It has been seen that, both solid dyed and yarn dyed samples the have gradually enhance its lightness value incongruence of the increase of pixel time at same dpi. As a result, among sample SD1 to SD3, laser effect at 50 microsecond pixel time on sample SD3 yields higher color difference which is 7.31 and 7.06 respectively under the light source D65 and TL84. In addition to that, as the untreated solid dyed fabric has pink hue so after laser printing on it the DH value has enhanced and saturation value (DC) and Da value has gradually decreased because the color intensity has attenuating by higher exposure of pixel time (Figure 2). 


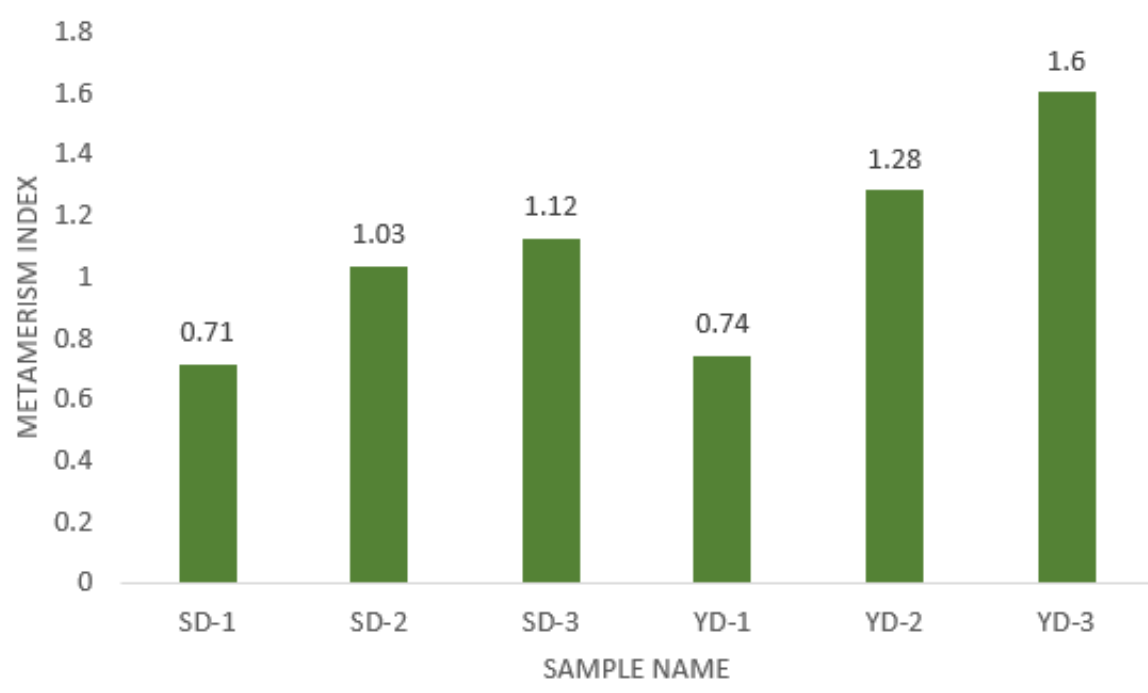

Figure 2: Metamerism index.

On the other hand, regarding yarn dyed fabric lightness value of $L$ has increase greater for exposing samples at 55 microsecond pixel time at both light source but the value of $\mathrm{Da}$ and $\mathrm{Db}$ has amplified as the samples are navy blue color. While alike solid dyed fabric (YD-
3) printing with higher pixel diminishing its color intensity. After math, value of color difference (17.45 and 18.73) is greater in case of YD-3 specimen compared to other samples.

Table 3: Color co-ordinate value of laser treated fabric.

\begin{tabular}{|c|c|c|c|c|c|c|c|c|c|c|c|c|}
\hline \multirow{2}{*}{ Name of the sample } & \multicolumn{6}{|c|}{ D65 } & \multicolumn{6}{|c|}{ TL84 } \\
\hline & DL & Da & $\mathrm{Db}$ & DC & DH & $\Delta \mathbf{E}$ & DL & Da & Db & DC & DH & $\Delta \mathrm{E}$ \\
\hline SD-1 & 7.79 & -2.53 & -1.45 & -2.9 & -0.31 & 4.18 & 7.68 & -2.03 & -1.65 & -2.59 & -0.36 & 4.07 \\
\hline SD-2 & 11.8 & -4.3 & -0.55 & -4.03 & 1.58 & 6.51 & 11.7 & -3.45 & -0.69 & -3.17 & 1.53 & 6.25 \\
\hline SD-3 & 13 & -4.74 & -0.24 & -4.2 & 2.2 & 7.31 & 12.89 & -3.81 & -0.34 & -3.18 & 2.12 & 7.06 \\
\hline YD-1 & 13.6 & 1.26 & 0.53 & -0.38 & 1.32 & 10.7 & 13.75 & 1.6 & 0.79 & -0.68 & 1.65 & 11.2 \\
\hline YD-2 & 16.7 & 1.28 & 4.8 & -4.48 & 2.13 & 13.9 & 17.11 & 1.89 & 5.66 & -5.34 & 2.68 & 14.8 \\
\hline YD-3 & 20.2 & 1.21 & 7.54 & -6.81 & -3.47 & 17.45 & 20.8 & 2 & 8.79 & -7.85 & 3.47 & 18.73 \\
\hline
\end{tabular}

SD1-SD3: Solid dyed samples after laser printing, and YD1-YD3: Yarn dyed samples after laser printing

Concerning the both solid dyed samples and yarn dyed samples, laser printed yarn dyed fabric at higher pixel time (YD-3) become more lighter and enervate its saturation value which eventually increase the value of $\Delta \mathrm{E}$ (Table 3).

\section{Metamerism Index (MI)}

Metamerism Index vary for all samples (solid and yarn dyed) at different pixel time. In regard to all specimen laser effect on yarn dyed fabric at higher pixel time provides greater metamerism Index that is 1.6. On the contrary, solid dyed sample at lower exposure of laser pixel shows the lowest (0.74) MI value which is slightly lower than yarn dyed samples at lower pixel time.

Resistance to pill formation is evaluated through pilling test.

\section{Method: JIS L 1076- 2006 A}

For solid dyed sample SD-1, slight surface fuzzing effect was seen. Rest of the samples (both solid dyed and yarn dyed) showed moderate fuzzing effect. But a small number of pills fall off in case of yarn dyed samples (Figure 3).

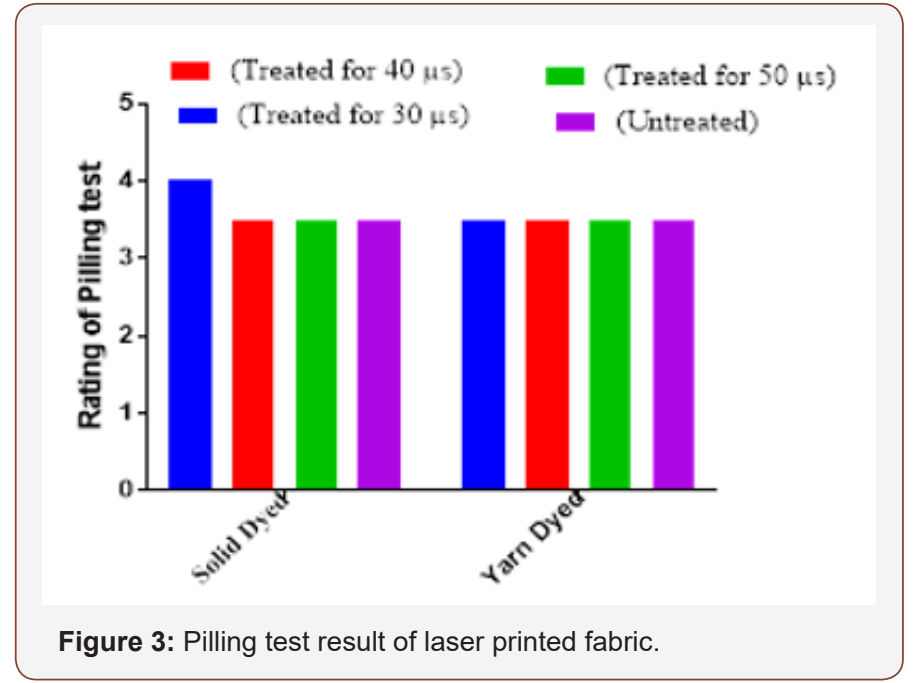

\section{ANOVA Analysis}

The P values for both column and row are greater than $\alpha=0.05$, that means we can reject null hypothesis and there are no significant 
changes in pilling resistance of before and after laser treatment (Tables 4\&5).

Table 4: Rating of pilling test of different samples.

\begin{tabular}{|c|c|c|c|c|}
\hline Samples & $\begin{array}{c}\text { (Treated } \\
\text { for } \mathbf{3 0} \boldsymbol{\mu s} \text { ) }\end{array}$ & $\begin{array}{c}\text { (Treated } \\
\text { for } \mathbf{4 0} \boldsymbol{\mu s} \text { ) }\end{array}$ & $\begin{array}{c}\text { (Treated } \\
\text { for } \mathbf{5 0} \boldsymbol{\mu s} \text { ) }\end{array}$ & (Untreated) \\
\hline Solid Dyed & 4 & 3.5 & 3.5 & 3.5 \\
\hline Yarn Dyed & 3.5 & 3.5 & 3.5 & 3.5 \\
\hline
\end{tabular}

Table 5: ANOVA analysis of abrasion pilling resistance.

\begin{tabular}{|c|c|c|c|c|c|}
\hline $\begin{array}{c}\text { ANOVA } \\
\text { table }\end{array}$ & SS & DF & MS & $\begin{array}{c}\text { F (DFn, } \\
\text { DFd) }\end{array}$ & P value \\
\hline Row Factor & 0.03125 & 1 & 0.03125 & $\mathrm{~F}(1,3)=1$ & $\mathrm{P}=0.3910$ \\
\hline $\begin{array}{c}\text { Column } \\
\text { Factor }\end{array}$ & 0.09375 & 3 & 0.03125 & $\mathrm{~F}(3,3)=1$ & $\mathrm{P}=0.5000$ \\
\hline
\end{tabular}

\section{Tearing Strength}

Values of tearing strength for different samples are detected by tearing test.

\section{Method: JISL 1096 Method D Pendulum}

Both untreated solid dyed (SD-4) and untreated yard dyed (YD-4) samples showed higher strength. With the increment of treatment time the value of tearing strength got decreased generally in warp and weft way for both solid dyed and yarn dyed samples. Overall yarn dyed samples showed higher tearing strength than solid dyed samples both in warp way and weft way (Figures $4 \& 5$ ).

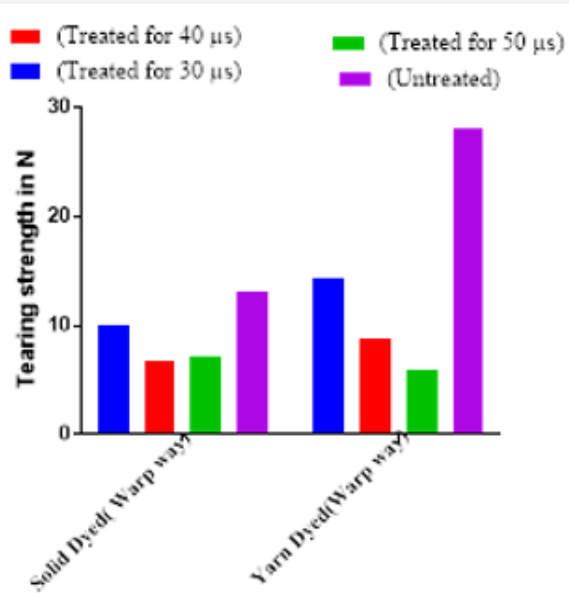

Figure 4: Tearing strength test at warp way.

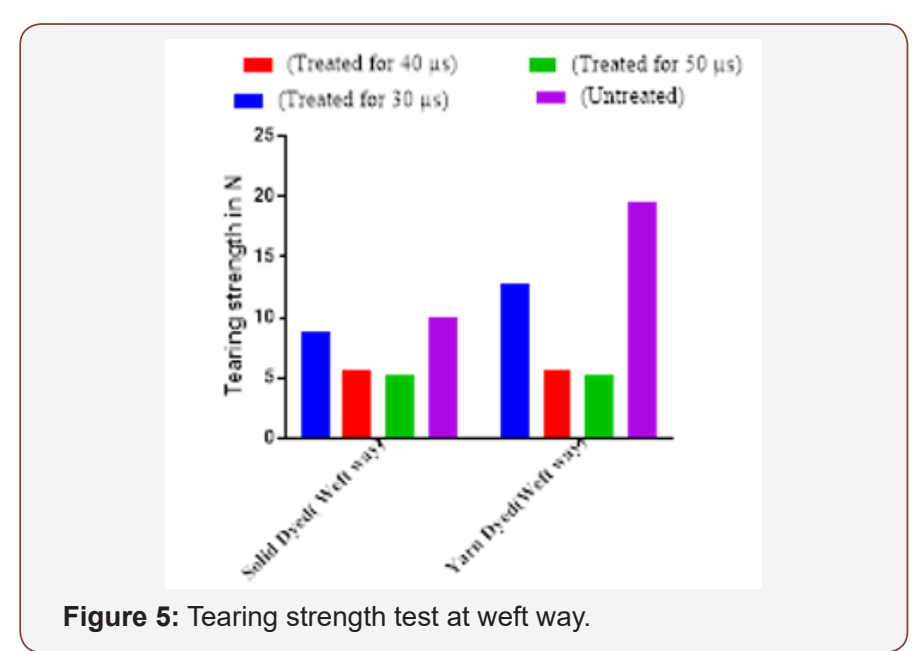

\section{ANOVA Analysis}

It has been seen from the above table, $\mathrm{P}$ values for both column and row are greater than $\alpha=0.05$, so reject null hypothesis and there is no significant variance in warp way tear strength for both solid and yard dyed sample before and after laser printing (Tables 6\&7). Table 6: Values of tearing strength for different samples in warp way.

\begin{tabular}{|c|c|c|c|c|c|}
\hline Samples & $\begin{array}{c}\text { (Treated } \\
\text { for } \\
\mathbf{3 0 \mu \mathrm { s } )}\end{array}$ & $\begin{array}{c}\text { (Treated } \\
\text { for } \\
\mathbf{4 0} \boldsymbol{\mu} \mathbf{s})\end{array}$ & $\begin{array}{c}\text { (Treated } \\
\text { for } \\
\mathbf{5 0} \boldsymbol{\mu s})\end{array}$ & $\begin{array}{c}\text { (Un- } \\
\text { treated) }\end{array}$ & P value \\
\hline Solid Dyed & 10 & 6.8 & 7.2 & 13.2 & $\mathrm{P}=0.3910$ \\
\hline Yarn Dyed & 14.4 & 8.8 & 6 & 28 & $\mathrm{P}=0.5000$ \\
\hline
\end{tabular}

Table 7: ANOVA Analysis (Warp Way tear strength).

\begin{tabular}{|c|c|c|c|c|c|}
\hline $\begin{array}{c}\text { ANOVA } \\
\text { table }\end{array}$ & SS & DF & MS & $\begin{array}{c}\text { F (DFn, } \\
\text { DFd) }\end{array}$ & P value \\
\hline $\begin{array}{c}\text { Row } \\
\text { Factor }\end{array}$ & 50 & 1 & 50 & $\begin{array}{c}\mathrm{F}(1,3)= \\
2.086\end{array}$ & $\mathrm{P}=0.2444$ \\
\hline $\begin{array}{c}\text { Column } \\
\text { Factor }\end{array}$ & 241.3 & 3 & 80.43 & $\begin{array}{c}\mathrm{F}(3,3)= \\
3.355\end{array}$ & $\mathrm{P}=0.1734$ \\
\hline
\end{tabular}

For weft way tear strength $\mathrm{p}$ values are also greater than 0.05 . So, we can reject null hypothesis. There is no significant variance.

From the ANOVA analysis it can be said that there is no significant difference in the terms of tear strength and abrasion pilling resistance for solid and yarn dyed fabric printing with different parameters of laser. So, laser printing can easily and effectively be used on fabric without any significant strength losses (Tables 8\&9).

Table 8: Values of tearing strength for different samples in warp way.

\begin{tabular}{|c|c|c|c|c|}
\hline Samples & $\begin{array}{c}\text { (Treated } \\
\text { for 30 } \boldsymbol{\mu s} \text { ) }\end{array}$ & $\begin{array}{c}\text { (Treated } \\
\text { for } \mathbf{4 0} \boldsymbol{\mu s} \text { ) }\end{array}$ & $\begin{array}{c}\text { (Treated } \\
\text { for 50 } \boldsymbol{\mu s} \text { ) }\end{array}$ & (Untreated) \\
\hline Solid Dyed & 8.8 & 5.6 & 5.2 & 10 \\
\hline Yarn Dyed & 12.8 & 5.6 & 5.2 & 19.6 \\
\hline
\end{tabular}

Table 9: ANOVA Analysis (Weft Way tear strength).

\begin{tabular}{|c|c|c|c|c|c|}
\hline $\begin{array}{c}\text { ANOVA } \\
\text { table }\end{array}$ & SS & DF & MS & $\begin{array}{c}\text { F (DFn, } \\
\text { DFd) }\end{array}$ & P value \\
\hline $\begin{array}{c}\text { Row } \\
\text { Factor }\end{array}$ & 23.12 & 1 & 23.12 & $\begin{array}{c}\mathrm{F}(1,3)= \\
2.24\end{array}$ & $\mathrm{P}=0.2314$ \\
\hline $\begin{array}{c}\text { Column } \\
\text { Factor }\end{array}$ & 125.7 & 3 & 41.89 & $\begin{array}{c}\mathrm{F}(3,3)= \\
4.059\end{array}$ & $\mathrm{P}=0.1400$ \\
\hline
\end{tabular}

\section{Conclusion}

In this study, color properties and physical properties were investigated for yarn dyed and solid dyed cotton fabric. $\Delta \mathrm{E}$ that is color difference from untreated fabric is highest for the YD-3 (yarn dyed 50 microseconds laser treated). Yarn dyed fabric at higher pixel time provides greater metamerism Index that is 1.6 and solid dyed sample at lower exposure of laser pixel shows the lowest (0.74) MI value. Tear strength also decreased with the higher pixel time lase treatment. But Laser treatment has not so much effect on pilling resistance all sample shows 3.5 rating except SD-1. Through ANOVA analysis it has been proved that there is no significant variation in tear strength and pilling resistance for before and after laser printed yarn and solid dyed sample. So, laser printing can be done very easily without any chemical both on solid and yarn dyed woven fabric without significant strength loss. 


\section{Acknowledgement}

None.

\section{Conflict of Interest}

Authors declare no conflict of interest.

\section{References}

1. Zhao F, Bernstein WZ., Naik G, Cheng GJ (2010) Environmental assessment of laser assisted manufacturing: case studies on laser shock peening and laser assisted turning. J Clean Prod 18 (13): 1311-1319.

2. Franco A, Lanzetta M, Romoli L (2010) Experimental analysis of selective laser sintering of polyamide powders: an energy perspective. J Clean Prod 18: 1722-1730.

3. Alert P (1997) 5567207 methods for making and fading textiles with lasers.

4. Nayak, Khandual (2010) Istook and Hwang 2001; Simmons and Istook 2003; Ortiz-Morales et al. 2003; Ozguney 2007; Bahtiyari 2011.

5. Kan CW, Yuen CW (2008) ITMA 07 Survey 14: dry surface finishing. Text Asia 39(6): 10-15.
6. Kan CW (2012) ITMA review 2011-finishing. Text Asia 43 (1): 15-24.

7. Fátima E, Helena A (2007) Effect of $\mathrm{CO}_{2}$ laser radiation on surface and dyeing properties of synthetic fibers. Res J Text Appar 11(3): 42-47.

8. Yuan GX, Jiang SX, Newton E, Fan JT, Au WM (2011) Fashion design using laser engraving technology. In: 8ISS Symposium panel on transformation, pp 65-66.

9. Ortiz-Morales M, Poterasu M, Acosta-Ortiz SE, Compean I, HernandezAlvarado MR (2003) A comparison between characteristics of various laser-based denim fading processes. Opt Lasers Eng 39(1): 15-24.

10. Hung ON, Chan CK, Kan CW, Yuen CW (2017) Effect of the $\mathrm{CO}_{2}$ laser treatment on properties of $100 \%$ cotton knitted fabrics. Cellulose 24 (4): 1915-1926.

11. Knitel D, Kesting W, Schollmeyer E (1997) Surface structuring of synthetic fibers by UV laser irradiation, part I: phenomenological report. Polym Int 43(3): 231-239.

12. Yip J, Chan K, Sin K, Lau KS (2006) Formation of periodic structures by surface treatments of polyamide fiber. Part I: UV excimer laser irradiation. Appl Surf Sci 253(5): 2637-2643. 